\title{
Intraosseous foreign body granuloma in rotator cuff repair with bioabsorbable suture anchor
}

\author{
T. Nusselt $\cdot$ S. Freche $\cdot$ H.-M. Klinger $\cdot$ \\ M. H. Baums
}

Received: 18 January 2010/Published online: 6 June 2010

(C) The Author(s) 2010. This article is published with open access at Springerlink.com

\begin{abstract}
Biodegradable implants lead to problems such as cyst formation, soft-tissue inflammation, loose implant fragments or local osteolysis. This report represents the first published case of an intraosseous foreign body granuloma in the humeral head after arthroscopic rotator cuff tear fixation with a poly-L-lactide (PLLA) suture anchor. A 48-year-old female patient presented with pain in her right shoulder. A refixation of her right supraspinatus tendon with a biodegradable suture anchor was performed 11 months ago at an external hospital. Laboratory tests showed normal values for C-reactive protein, leukocytes and the erythrocyte sedimentation rate. No signs of infection or instability were noted. The visual analogue scale (VAS) was 8, the simple shoulder test (SST) was 4 and the American shoulder and elbow surgeons score (ASES) was 44. Plain radiographs showed high lucency in the area of the tuberculum majus. MRI showed an intra- and extraosseous mass surrounded by fluid in this area. Surgical care involved arthroscopic debridement and removal of the suture anchor. Histological examination revealed a foreign body granuloma. At the 18-month follow-up the patient was nearly pain-free. The VAS was 2, SST was 10 and ASES was 88. Foreign body granulomas are a well known but rarely described complication that arises after the use of biodegradable suture anchors in shoulder surgery. Every patient presenting with shoulder pain after usage of a biodegradable fixation material should be evaluated closely. Orthopaedic surgeons should be aware of the
\end{abstract}

T. Nusselt $\cdot$ S. Freche $\cdot$ H.-M. Klinger $\cdot$ M. H. Baums ( $\square)$ Department of Orthopaedic Surgery, University of Göttingen, Medical Center (UMG), Robert-Koch-Str. 40,

37099 Göttingen, Germany

e-mail: mbaums@t-online.de possibility of delayed foreign body reactions, especially after using PLLA anchors.

Keywords Foreign body granuloma - Bioabsorbable . Suture anchor $\cdot$ Shoulder $\cdot$ Rotator cuff tear

\section{Introduction}

A broad array of approaches to reconstructive shoulder surgery has been presented in the literature. The progress possible with suture anchors has opened new possibilities in the operative treatment of rotator cuff tear and shoulder instability. The arthroscopic scope [1, 2] is particularly suitable for use with these devices, because it provides primary stability $[3,4]$. The decision to use non-absorbable or biosabsorbable anchors is also important.

Biodegradable suture anchors lead to fewer artifacts in MRI during postoperative diagnostics and facilitate revision surgery [2]. Biodegradable suture anchors also provide primary stability equivalent to that of non-degradable suture anchors [5]. The pullout strengths of metallic and bioabsorbable implants are nearly comparable [2]. Thus, biodegradable implants are commonly used to treat this type of injury.

However, biodegradable implants lead to other problems, such as cyst formation, soft-tissue inflammation, loose implant fragments in the joint and local osteolysis [6-8]. The causal factors associated with these phenomena appear to be biochemical design and degradation time. The rates of degradation of different polymers vary widely: only a few months for polyglycolide (PGA) and up to 5 years or more for poly-L-lactide (PLLA) [9-12].

The first generation of biodegradable implants, made of polyglycolic acid, absorbs too fast and causes foreign body 
reactions [13]. The following generation of implants was composed of poly-L-lactic acid and did not degrade as fast as PGA [14, 15], which allowed sufficient healing before resorption [16].

Cases involving osteolysis and foreign body reaction following shoulder surgery after using biodegradable suture anchors are rare [2, 14, 16-18].

Here, we present for the first time the case of an intraosseous foreign body granuloma in the humeral head after arthroscopic rotator cuff tear fixation (supraspinatus tendon) with a PLLA suture anchor.

\section{Case report}

A 48-year-old female patient presented with pain in her right dominant shoulder. She described pain radiance to her right upper arm, exacerbation while exercising and nightly pain. Analgesia and physiotherapy did not lead to improvement. There was no history of trauma. She reported refixation of her right rotator cuff due to supraspinatus tendon rupture, performed with a biodegradable suture anchor 11 months ago at an external hospital.

Upon examination, she had a plain scar and no signs of infection. No atrophy of the surrounding muscles was noted. There was no evidence of instability. The Hawkins impingement and Neer tests were positive. There was no clinical sign of a rotator cuff re-rupture. Laboratory tests for C-reactive protein, leukocytes and the erythrocyte sedimentation rate (ESR) were normal.

The visual analogue scale (VAS) score was 8 , the simple shoulder test (SST) was 4 and the American shoulder and elbow surgeons score (ASES) was 44. Concerning the range of motion, she had a $\mathrm{Ab} / \mathrm{Ad}: 100^{\circ} / 0^{\circ} / 20^{\circ}$, Flex/Ext: $110^{\circ} / 0^{\circ} / 30^{\circ}$ and IR/ER: $60^{\circ} / 0^{\circ} / 20^{\circ}$.

Plain radiographs revealed high lucency in the area of the tuberculum majus (Fig. 1). MRI showed an intra- and extraosseous mass of approximately $7 \mathrm{~mm}$ in size, surrounded by fluid in the area encompassing the tuberculum majus. There was also visible radiocontrast agent enhancement in the areas surrounding the humeral head and the rotator cuff below the supraspinatus tendon (Fig. 2).

An arthroscopic debridement and partial synovectomy were performed. Removal of the partial degraded suture anchor (PANALOK RC QuickAnchor Plus ${ }^{\circledR}$ ) (Fig. 3) and refixation of the supraspinatus tendon by an intraosseous stitch were then performed, using a mini-open approach. Postoperative treatment was similar to our normal approach to treatrotator cuff tear rehabilitation.

Histological examination of the tissue from the bony defect in the tuberculum majus revealed papillary hyperplastic synovia and a foreign body giant cell reaction in the spongiose bone attached to the PLLA suture anchor.

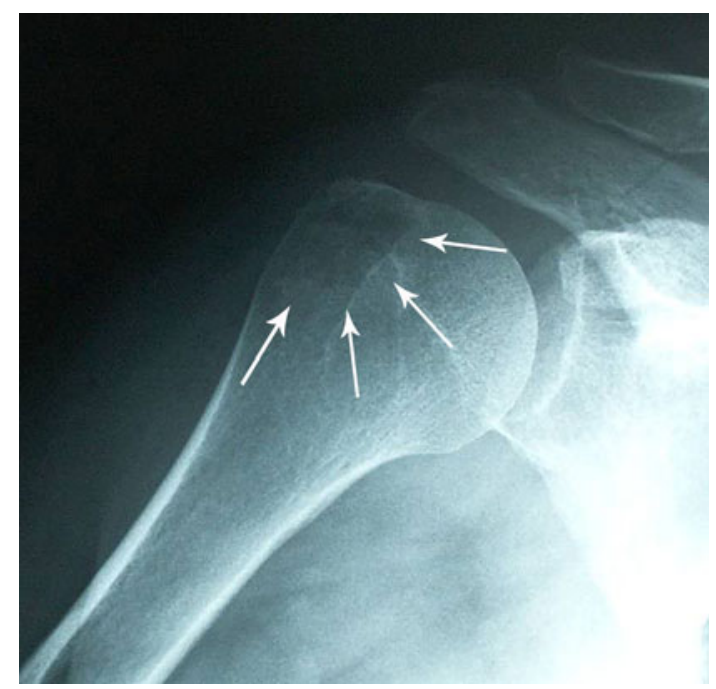

Fig. 1 Plain anteroposterior radiograph of the right shoulder demonstrating osteolysis in the tuberculum majus after rotator cuff refixation 11 months prior

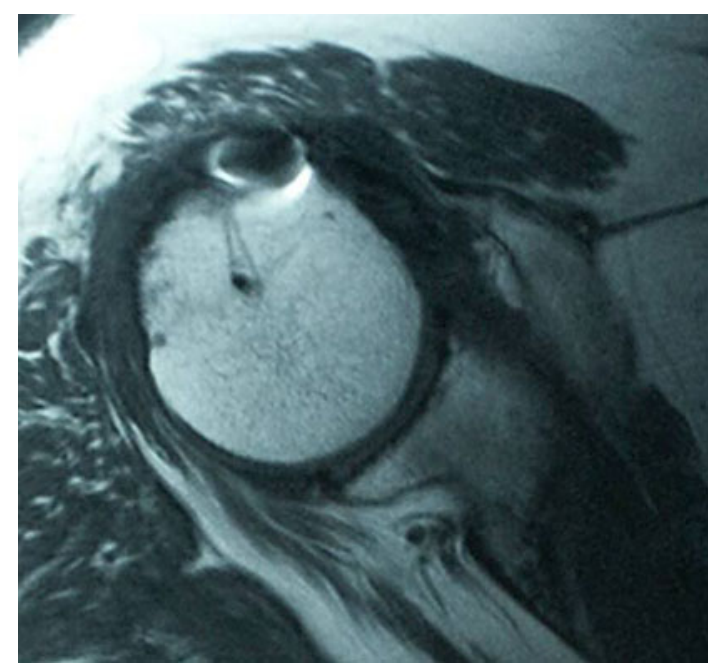

Fig. 2 Coronal MRI of the right shoulder demonstrating the intraand extraosseous mass in the humeral head

At the 18-month follow-up, the patient was nearly painfree. The Hawkins and Neer impingement tests were negative. The VAS score was 2 , the SST was 10 and the ASES was 88 . The plain radiographs after this time revealed full regression of the osteolysis.

\section{Discussion}

The usage of arthroscopic reconstructive procedures in shoulder surgery increasingly requires multiple implants. The arthroscopic scope [1,2] derives its high level of primary stability $[3,4]$ and convenience from the use of suture anchors, as opposed to simple suture techniques. 


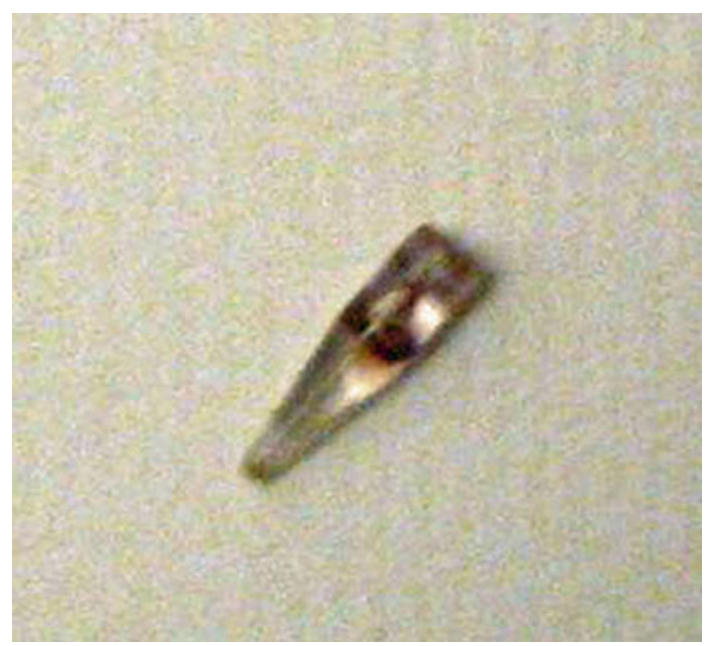

Fig. 3 PANALOK RC QuickAnchor Plus ${ }^{\circledR}$ after removal

Over recent decades, metal anchors have been replaced by bioabsorbable anchors. Bioabsorbable suture anchors can offer the advantage of reabsorption and may avoid certain problems inherent to metal anchors, such as artifacts on MRI scans [7, 8, 19, 20]. Additionally, bioabsorbable sutures facilitate revision surgery, avoid the risk of dislocation with permanent fixation gadgets and posses equivalent primary stability to non-degradable suture anchors $[5,21]$.

Therefore, the use of biodegradable implants has become a common treatment in shoulder stabilization and rotator cuff refixation.

The biodegradable suture anchors that are available differ in polymer composition, which affects the time to reabsorption [22]. The rates of degradation vary widely among polymers, from only a few months for polyglycolide (PGA) to up to 5 years or more for poly-L-lactide (PLLA) [9-12]. The first generation, made of polyglycolic acid, absorbs too fast and causes foreign body reactions [13]. The following generation of implants was composed of poly-L-lactic acid and did not degrade as fast as polyglycolic acid [14, 15], which allowed sufficient healing before reabsorption of the anchor [16]. Anchor degradation should ideally occur as soft tissue healing progresses [21].

When considering the use of biodegradable suture anchors, it is important to know the rate of soft tissue healing to bone, and the time it takes the anchor used to be degraded. This time-point determines the onset of stress to the surgical construct [2]. If the interface of soft tissue and bone is not rigid, healing may not occur [4, 23].

However, biodegradable implants lead to other problems, such as cyst formation, soft-tissue inflammation, loose implant fragments in the joint and local osteolysis or foreign body granulomas $[6-8,13,14,16]$. The biochemical design seems to be one causal factor [11, 22, 24, 25].

Rokkanen et al. [26] described the occurrence of noninfectious foreign body reactions after $2-3$ months in patients who received polyglycolide implants. This reaction has been observed in $2 \%$ of patients who received polyglycolide implants but hardly ever in patients who received polylactide implants.

Freehill et al. [14] noted a substantial number of foreign body reactions, resulting in synovitis and multiple small osteolytic lesions at the implantation site after using PLLA tack fixation for arthroscopic shoulder stabilization. The average time after the first surgery until the appearance of symptoms was 8 months. Operative treatment consisted of arthroscopic evaluation, debridement, complete synovectomy and implant removal. At follow-up after more than 1 year, $70 \%$ of patients reported a full return of motion and no or minimal pain.

Glueck et al. [16] presented a case with the development of extensive osteolysis in the humeral head 8 months after suture anchor fixation. The authors fixed a rotator cuff tear and repaired a SLAP lesion with a poly (L-lactide-co-D, L-lactide) (PLDLA) anchor. This patient was asymptomatic and did not require reoperation. At the 16-month followup, the patient was still asymptomatic and the radiographs demonstrated no lytic changes.

Spoliti et al. [2] reported an osteolysis in the superior pole of the glenoid 10 months after arthroscopic repair of a SLAP lesion with a PLLA anchor. The authors performed an arthroscopic debridement and used a non-absorbable anchor for repair. This patient was free of symptoms, and there was no evidence of recurrence at the 6-month followup.

We present the first case of poly-L-lactic acid suture anchor fixation of an isolated rotator cuff tear (supraspinatus tendon) that led to the development of an intraosseous foreign body granuloma in the humeral head.

The mechanism underlying the formation of this foreign body granuloma is not clear. It could be a reaction to the polymer structure of the PLLA suture anchor [14]. Potential causal factors such as alteration of the implant due to sterilization, focal necrosis due to drilling or micromotion of the anchor should also be considered [16, 27]. Numerous studies have shown that biodegradable materials are a good option in capsuloligamentous refixation [2], exhibiting multiple advantages and a low incidence of complications $[21,27]$. The pathways described in the present and previous cases demonstrate similarities concerning the time between surgery and symptoms, radiological signs, treatment and recovery. Further studies will reveal the relationship between material-induced and external-induced influences on the development of a foreign body granuloma. 


\section{Conclusion}

Foreign body granulomas after the use of biodegradable suture anchors in shoulder surgery is a well known but rarely described complication. Every patient presenting with pain in the shoulder after usage of a biodegradable fixation material should be carefully evaluated. Orthopedic surgeons should be aware of the possibility of late foreign body reactions, especially after using PLLA anchors.

Conflict of interest statement The authors declare that they have no conflict of interest.

Open Access This article is distributed under the terms of the Creative Commons Attribution Noncommercial License which permits any noncommercial use, distribution, and reproduction in any medium, provided the original author(s) and source are credited.

\section{References}

1. Scheibel MT, Habermeyer P (2003) A modified Mason-Allen technique for rotator cuff repair using suture anchors. Arthroscopy 19:330-333

2. Spoliti M (2007) Glenoid osteolysis after arthroscopic labrum repair with a bioabsorbable suture anchor. Acta Orthop Belg 73:107-1010

3. Klinger HM, Buchhorn GH, Heidrich G, Kahl E, Baums MH (2008) Biomechanical evaluation of rotator cuff repairs in a sheep model: suture anchors using arthroscopic Mason-Allen stitches compared with transosseous sutures using traditional modified Mason-Allen stitches. Clin Biomech 23:291-298

4. McFarland EG, Park HB, Keyurapan E, Gill HS, Selhi S (2005) Suture anchors and tacks for shoulder surgery, part 1. Am J Sports Med 33:1918-1923

5. Goradia VK, Mullen DJ, Boucher HR, Parks BG, O’Donnell JB (2001) Cyclic loading of rotator cuff repairs: a comparison of bioabsorbable tacks with metal suture anchors and transosseous sutures. Arthroscopy 17:360-364

6. Burkhart SS (2005) Letter to the editor. Am J Sports Med 33:11

7. McGuire DA, Barber FA, Elrod BF, Paulos LE (1999) Bioabsorbable interference screws for graft fixation in anterior cruciate ligament reconstruction. Arthroscopy 15:463-473

8. Weiler A, Windhagen HJ, Raschke MJ, Laumeyer A, Hoffmann RF (1998) Biodegradable interference screw fixation exhibits pull-out force and stiffness similar to titanium screws. Am J Sports Med 26:119-127

9. Böstman OM (1991) Current concepts review: absorbable implants for the fixation of fractures. J Bone Joint Surg 73A:148-153

10. Böstman O, Päivärinta U, Partio E, Vasenius J, Manninen M, Rokkanen P (1992) Degradation and tissue replacement of an absorbable polyglycolide screw in the fixation of rabbit femoral osteotomies. J Bone Joint Surg 74-A:1021-1031

11. Bergsma EJ, de Bruijn WC, Rozema FR, Bos RRM, Boering G (1995) Late degradation tissue response to poly(L-lactide) bone plates and screws. Biomaterials 16:25-31
12. Suuronen R, Pohjonen T, Hietanen J, Lindqvist C (1998) A 5-year in vitro and in vivo study of the biodegradation of polylactide plates. J Oral Maxillofac Surg 56:604-614

13. Böstman OM, Pihlajamaki HK (2000) Adverse tissue reactions to bioabsorbable fixation devices. Clin Orthop Rel Res 371:216-227

14. Freehill MQ, Harms DJ, Huber SM, Atlihan D, Buss DD (2003) Poly-L-lactic acid tack synovitis after arthroscopic stabilization of the shoulder. Am J Sports Med 31:643-647

15. Peltoniemi H, Ashammakhi N, Kontio R, Waris $\mathrm{T}$, Salo A, Lindqvist C, Grätz K, Suuronen R (2002) The use of bioabsorbable osteofixation devices in craniomaxillofacial surgery. Oral Surg Oral Med Oral Pathol Oral Radiol Endod 94:5-14

16. Glueck D, Wilson TC, Johnson DL (2005) Extensive osteolysis after rotator cuff repair with a bioabsorbable suture anchor. Am J Sports Med 33:742-744

17. Müller M, Kääb MJ, Villiger C, Holzach P (2002) Osteolysis after open shoulder stabilization using a new bio-resorbable bone anchor: a prospective, non-randomized clinical trial. Injury 33:30-36

18. Athwal GS, Shridharani SM, O’Driscoll SW (2006) Osteolysis and arthropathy of the shoulder after use of bioabsorbable knotless suture anchors. J Bone Joint Surg Am 88:1840-1845

19. Benedetto KP, Fellinger M, Lim TE, Passler JM, Schoen JL, Willems WJ (2000) A new bioabsorbable interference screw: preliminary results of a prospective, multicenter, randomized clinical trial. Arthroscopy 16:41-48

20. Barber FA, Snyder SJ, Abrams JS, Fanelli GC, Savoie FH 3rd (2003) Arthroscopic Bankart reconstruction with a bioabsorbable anchor. J Shoulder Elbow Surg 12:535-538

21. Warme WJ, Arciero RA, Savoie FH 3rd, Uhorchak JM, Walton M (1999) Nonabsorbable versus absorbable suture anchors for open Bankart repair. A prospective, randomized comparison. Am J Sports Med 27:742-746

22. Böstman OM, Pihlajamäki HK (1998) Late foreign-body reaction to an intraosseous bioabsorbable polylactic acid screw. A case report. J Bone Joint Surg 80:1791-1794

23. Meyer DC, Gerber C (2004) Failure of anterior shoulder instability repair caused by eyelet cutout of absorbable suture anchors. Arthroscopy 20:521-523

24. Pihlajamäki H, Böstman $\mathrm{O}$, Hirvensalo E, Tömälä $\mathrm{P}$, Rokkanen $\mathrm{P}$ (1992) Absorbable pins of self-reinforced poly-L-lactic acid for fixation of fractures and osteotomies. J Bone Joint Surg 74:853857

25. Matsusue Y, Hanafusa S, Yamamuro T, Shikinami Y, Ikada Y (1995) Tissue reaction of bioabsorbable ultra high strength poly (L-lactide) rod. A long-term study in rabbits. Clin Orthop 317:246-253

26. Rokkanen PU, Böstman O, Hirvensalo E, Mäkelä EA, Partio EK, Pätiälä H, Vainionpää SI, Vihtonen K, Törmälä P (2000) Bioabsorbable fixation in orthopaedic surgery and traumatology. Biomaterials 21:2607-2613

27. Kääb MJ, Rahn BA, Weiler A, Curtis R, Perren SM, Schneider E (2002) Osseous integration of poly-(L-Co-D/L-lactide) 70/30 and titanium suture anchors: an experimental study in sheep cancellous bone. Injury 33:B37-B42

28. Lohrbach O, Wilmes P, Brogard P, Seil R (2008) Complications related to implants in arthroscopic shoulder surgery [German]. Orthopäde 37:1073-1079 